\title{
Exploration on Comprehensive Utilization Technology of Mine Tailings
}

\author{
Ge ri le $\mathrm{l}^{1.2}$, Su Liang Yan $^{3}$ \\ ${ }^{1}$ HulunBuir,University HulunBuir,Hailar, \\ ${ }^{2}$ Engineering Research Center for the Safe Exploitation and Comprehensive Utilization of \\ Mineral Resources at Universities of Inner Mongolia Autonomous Region HulunBuir,Hailar \\ ${ }^{3}$.Inner Mongolia Autonomous Region, The sixth institute of Geology and mineral exploration and development Hulun Buir, Hailar
}

\begin{abstract}
With the stable and sustained development of the domestic economy, the demand for various mineral resources is increasing. Mineral resources have great value for social and economic development. Mineral resources provide the vast majority of raw materials for domestic economic development. However, in the actual mining process, many beneficial substances are discarded in the form of tailings. After a long period of extensive mining, the amount of domestic minerals has gradually decreased. Outdated mining methods lead to a substantial increase in costs, while leaving many mine tailings. The insufficient utilization of tailings has formed many obstacles to the sustainable development of the industry. Many components of tailings are still valuable, so they must be turned into waste. Vigorously carry out the recycling of resources and promote the common development of the economy and the environment. We are supposed to attach importance to the ecological environment and adverse effects of tailings, and adopt scientific measures to reduce the adverse effects of tailings on the ecological environment.
\end{abstract}

\section{Introduction}

Mineral resources include metal ores and non-metal ores, which are important materials for human survival. There are many types of ore in China, but the grade of ore is barren. There are fewer ore resources of a single species, and the ore element composition is very complicated. After mining, a large amount of tailings are left. Most of them are treated as industrial waste, causing serious waste of resources and environmental pollution. At the 19th National Congress of the Party, the requirements for comprehensive resource conservation and recycling were clearly set out. Actively promote the reform of waste treatment and make more contributions to the development of an ecologically civilized society. This article is mainly aimed at the exploration of mine tailings comprehensive utilization technology, and puts forward opinions and suggestions based on the actual situation.

\section{Status and Necessity of Comprehensive Utilization of Tailings}

\subsection{Situation Analysis}

The traditional extensive economic law development model has led to over-exploitation of mines, which causes not only a sharp consumption of mineral resources, but also serious environmental problems. A large number of tailings have been discarded as industrial solid waste. According to some statistics, domestic tailings have reached 5.97 billion tons. The most widely used iron tailings stockpiles have reached more than one billion tons, causing a very serious waste of resources. Every year, a large number of tailings are piled up and occupied a large amount of land, which also destroys the local ecological environment. Domestic tailings utilization technology needs to be improved, such as huge consumption, large waste and low utilization rate. Not only the economic benefits are reduced, but also a huge threat to the lives of local people. Further strengthening the utilization efficiency of tailings has great value for the development of the entire industry. Secondly, tailings are the largest source of domestic solid waste ore, which has a huge impact on the ecological environment. Obstructed the sustainable development of the economy, but also left many security risks. Only after the traditional mine is mined, because the technology is not advanced enough, the resource recovery rate is low. With the rapid development of technology, the comprehensive utilization of tailings has become a hot topic. However, in the actual management process, many problems were encountered. The production volume of tailings is huge, and the actual utilization efficiency needs to be improved Most of the tailings are accumulated in the tailings depot, which has not attracted the attention of enterprises. The mining technology of tailings is limited, and there is a lack of more professional and effective technical means. Most people are unaware of the negative effects of 
tailings and turn a blind eye to the piles of tailings. Relevant departments have insufficient supervision over the comprehensive utilization of tailings and lack a relatively comprehensive management policy. The degree of utilization of household tailings needs to be gradually improved, and technical equipment must be actively improved to make more contributions to improving the ecological environment.

The domestic economy is in a critical period of transformation, and the pursuit of economic benefits from industrial production is still mainstream. Some companies are reluctant to abandon the extensive economic development model, and the backward thinking of using the environment for the economy still exists. The utilization rate of tailings resources is low, which poses a huge threat to the surrounding ecological environment.

\subsection{Necessity Analysis}

The rapid increase in the number of domestic tailings has led to more and more obvious mineral resources. Tailings can improve the utilization of mineral resources and make more contributions to economic development. The necessity of comprehensive utilization of tailings can be summarized as follows: 1. Domestic per capita mineral resources are relatively small. China's total resources are abundant, but the per capita resource gap is obvious. With the rapid development of the domestic economy, the extensive development model has caused serious environmental problems. In particular, the waste of mineral resources has caused serious environmental pressures near the mines. 2. Tailings contain a lot of metal and non-metal elements. In the past, the domestic mineral processing technology was very backward, and there were other elements after the single mineral processing. With the rapid development of science and technology, the extraction of other elements in tailings has become more convenient. For example, the average iron grade in iron ore tailings is $10 \%-12 \%$, and direct abandonment will cause huge waste. 3. Tailings cause environmental pollution. The tailings not only contain a large amount of metal elements, but also are rich in heavy metal ions, which are mainly the residues of chemicals added during the beneficiation process. The heavy metal ions in the tailings will penetrate into the soil, causing pollution to the water resources around the mining area and posing a huge threat to the ecological environment. 4. Construction of tailings requires a lot of capital investment. Most domestic tailings are discarded as industrial waste. Not only does the construction of a tailings pond require a large amount of capital, it also occupies a large amount of land. Comprehensive utilization of tailings is an important measure for the strategic security of resources, and it also has irreplaceable value for ecological environmental protection.

The comprehensive utilization of tailings has great value for improving the surrounding ecological and geological environment. Tailings have large amounts of sand and fine particles, which often cause problems such as collapse and dam failure due to poor management. A large amount of rainwater accumulates in the tailings reservoir, which is likely to cause serious waste of water resources. Multi-level impacts have led to increasing difficulties in the management of tailings reservoirs, and it is imperative to improve the comprehensive utilization efficiency of tailings. Both stacked tailings and output tailings have huge potential value. Actively improving tailings utilization efficiency provides new ideas for economic transformation. Tailings can be used as concrete admixtures, which can greatly increase the supply of mineral admixtures for concrete in the region. The tailings are used as aggregate in concrete, which solves the problem of tailings accumulation. At the same time, it also provides alternative resources for building materials, reduces the degree of environmental pollution, and has great value for the comprehensive utilization of tailings resources.

\section{Increase The Comprehensive Utilization Value of Tailings Resources}

\subsection{Fully Explore the Potential Value of Tailings Resources}

At the stage of tailings development and utilization, the existing value of the mine resources must be clarified. We can clarify the underlying value basis and make full use of tailings resources. In the actual application process, the potential value of tailings resources should be fully tapped, and the value of tailings should be maximized. For example, metal tailings, because of the different types of metals, the actual use is different. Targeted development and utilization of tailings can add new impetus to economic development.

\subsection{Minimize the Impact on the Ecological Environment}

Discussing the comprehensive utilization of mine tailings also belongs to environmental protection work. Regardless of tailings storage or development and utilization, we must attach importance to ecological protection. It is also an important principle of tailings utilization to reduce the impact on surrounding ecology and environment as much as possible. At the actual stage of tailings construction, it is necessary to attach great importance to the isolation of the tailings pond and groundwater to prevent any form of water pollution. In tailings, there are also a lot of harmful elements. In the purification process, it is necessary to avoid the destruction and pollution of these elements. In the process of tailings storage, it is necessary to pay attention to the impact of tailings on the environment. The environmental protection concept to ensure comprehensive utilization of tailings can be effectively reflected.

\subsection{Pay Attention to the Classification of Tailings Utilization}


In the actual tailings comprehensive utilization phase, the classification treatment is also a principle that cannot be ignored. There are many types of tailings, so we must pay attention to the classification and utilization in the actual application process. Classification of resources according to use, so that tailings resources can fully play a role. We need to select appropriate classification and treatment methods to avoid the mutual influence of different types of tailings resource utilization stages, and further improve the tailings utilization efficiency.

\section{Problems Encountered in the Comprehensive Utilization of Tailings}

\subsection{Tailings Resource Information is Incomplete}

In the actual comprehensive utilization phase of tailings, resources and information are insufficient. The difficulty of comprehensive utilization of tailings continues to increase, causing huge obstacles to the subsequent work. None of the competent authorities have complete tailings information, and no cross-industry database has been formed. The tailings use plan is developing slowly, and there is a lack of information that can be relied upon during the tailings resource development stage. The development and utilization of tailings resources are very blind and arbitrary, which directly affects the development of the industry.

\subsection{Low Comprehensive Utilization}

Combined with relevant statistical data for analysis, the comprehensive utilization rate of domestic beneficial components of tailings is less than $2.5 \%$. The value of the symbiotic and associated components of some tailings is higher than that of the mineral itself, but it has not been paid much attention in the actual application process, and the comprehensive utilization of tailings is low.

\subsection{Insufficient Support}

Domestic tailings are more used in industry, but the application of tailings is still at the level of recovery of valuable elements. Or as a substitute for sand and gravel, the actual utilization efficiency is still very low. Some companies use it as a raw material for high-end building materials, but they lack competitiveness due to higher costs. Mining companies attach importance to short-term benefits, and do not pay enough attention to the comprehensive utilization of tailings. The actual support is insufficient, resulting in very few high-added products in the tailings utilization process. The lack of corresponding policy support has not significantly improved the comprehensive utilization rate of tailings.

\section{Channel Analysis of Comprehensive Utilization of Tailings}

\subsection{Tailings Reselection}

With the rapid development of the mining industry, the number of tailings has been increasing. To maintain long-term economic benefits and reduce environmental pollution, the use of tailings resources is very important. Combined investigations and studies have shown that tailings contain mineral colloids that are active, electrical, absorbent, and highly energy efficient. In the comprehensive utilization of tailings, valuable elements are better screened out through tailings. Under alkaline conditions, it can be combined with the ions of the cement slurry to show the characteristics of aggregates, thus exerting a new role. Mineral resources are non-renewable, and the current socio-economic dependence on mineral resources is very high. The tailings re-selection method is used to further improve the utilization of valuable elements.

\subsection{As Downhole Filling}

When conveying tailings downhole, concrete pumps can be used to backfill the goaf carefully. On the basis of cement filling or water-sand filling, cement or other cementitious materials need to be added for backfilling. Fill cementation to ensure that loose tailings can aggregate into a whole. At the same time, the tailings in the goaf are filled with filler and the effect is significant, which can improve the utilization rate of the mine tailings.

\subsection{As A Filler}

Tailings can be used for backfilling the mined-out area of the mining area, reducing the cost of refilling. The release of a large amount of occupied land also reduces the impact on the ecological environment. Reduce the probability of ground subsidence, and safeguard the lives and property of local people. The mined-out area will affect the stability of the mining area, and at the same time, it will be easier to induce disasters such as landslides and collapses. After mining is completed in time, tailings are a good filling material. The tailings are filled with waste data and the model of in-situ material extraction has greatly reduced costs and made more contributions to environmental protection. In the tailings filling stage, it is necessary to add appropriate additives such as expansion materials to ensure a good filling effect.

\subsection{Made of Fertilizers and Soil Conditioners}

Tailings can be used as fertilizers and soil improvers, because tailings contain a large amount of copper, zinc, iron and other trace elements, which have a significant effect on plant growth. The beneficial elements in the tailings are extracted to formulate fertilizers and contribute to the development of agricultural economy. In addition, tailings can be used as soil improvers to achieve true comprehensive utilization. Such as the use of a magnetizer for processing, adding it to the soil to improve the magnetic properties. The soil structure and air permeability are improved, and good conditions are 
created for plant growth.

\subsection{Preparation of Microcrystals}

The structure of microcrystals is special and is widely used in scientific research. Researches on microcrystals have achieved certain achievements, but many problems have been encountered in the manufacturing process of microcrystals. Tailings contain various elements, which are extracted into microcrystals. For example, amorphous white carbon black is prepared by iron tailings, so microcrystals will also become an important way for comprehensive utilization of tailings.

\subsection{Tailings Reclamation}

At present, most tailings are stored in tailings ponds, which will be closed after the corresponding years of service. Tailings reclamation involves covering the slope with soil and planting cash crops. This will not only reduce the pollution to the natural environment, but also increase the cultivated area.

\section{Conclusion}

In summary, it is necessary to explore the comprehensive utilization technology of mine tailings. Vigorously carry out the recycling of resources and promote the common development of the economy and the environment. The necessity of comprehensive utilization of tailings was clarified, and theoretical support was provided for the subsequent work. According to the current status of tailings and the status of comprehensive utilization of tailings, strictly follow the principle of comprehensive utilization of tailings and formulate a scientific response plan. Targeted development and utilization of tailings can add new impetus to economic development.

\section{References:}

1. Wu Jinbiao, Diao Zenghui. Advances in mine tailings treatment technology and resource utilization [J]. Environment, 2017, (21): 29-32.

2. Hui Xuede, Xie Jiyuan. Paste technology and its application in tailings treatment [J]. China Mining Engineering, 2018, 40 (2): 49-54.

3. Chen Dianzhu. Analysis and research on solid mine tailings storage technology and comprehensive utilization [J]. Hunan Nonferrous Metals, 2016, 32 (4): 5-8.

4. Zhao Nan, Lv Xianjun, Liang Zhiqiang, etc. Progress in comprehensive recovery technology of gold mine tailings [J] .Gold, 2017, (3): 71-74, 75.

5. Zhang Guangwei, Tong Lijuan, Li Zeli, et al. Discussion on the treatment method and development of ultrafine tailings [J]. Metal Mines, 2017, (2): 171-177.

6. Guo Juling. Gold Mine Tailings Treatment Technology [J]. Science and Technology Innovation Herald, 2017, (14): 73.
7. Yu Chao, Sha Xingmin. Talking about the treatment and application of tailings [J]. Brick and Tile World, 2018, (10): 5, 25. 